\title{
Patrimonio documental. Las Normas de Descripción Archivística: encuentros y "desencuentros"
}

\section{Antonia Heredia Herrera}

Directora del Archivo General de Andalucía

Resumen

La descripción archivística es una manifestación específica del análisis documental aplicado a los documentos de archivo. Las exigencias de estandarización para tal fin han llevado a la elaboración, a nivel internacional, de dos normas: la $\operatorname{ISAD}(G)$ y la ISAAR(CPF).

Se analizan en este artículo el texto y contenidos de la segunda versión de la Norma $\operatorname{ISAD}(\mathrm{G})$ que, entre otras conclusiones, recomienda a los diferentes países la confección de Normas Nacionales para la descripción archivística, compatibles con aquéllas.

Un grupo de trabajo convocado por el Ministerio de Cultura y con representación de todas las Comunidades autónomas está comprometido en su redacción, en el plazo de dos años. Dichas Normas serán aplicadas, en nuestro caso, a la confección del Censo de fondos y colecciones del Patrimonio documental andaluz.

\section{Palabras clave}

Descripción archivística / Archivos / Patrimonio documental / Estandarización / ISAD(G).

\section{Introducción}

Stefano Vitali, al hacer un análisis de las ventajas de la segunda versión de la Norma ISAD(G)I, en un afán de resaltar sus excelencias, desmesura -como si se tratará de un andaluz- la incuria inmediatamente anterior, en materia de descripción, ofreciendo una imagen desértica de vacío generalizado que contrapone a los logros de la estandarización que califica de "proceso histórico único". Según nuestro colega italiano, en los años 80, ni siquiera éramos capaces de reconocer que un fondo tenía elementos comunes con otros fondos y por tanto, éramos incapaces de elaborar instrumentos de descripción con características semejantes.

No creo que esto sea exactamente así, por lo que a nosotros afecta, pero no voy a entrar en este debate y simplemente voy a situarme quince años después en nuestro país, en una realidad que no puede ser fruto de un año, ni de varios, sino que representa una evolución, una asimilación teórica y práctica que ha tenido lugar en un plazo que, sin duda, tiene que adelantarse bastante a los años ochenta, aludidos por Vitali2.

En 1995, cuando se difunde en España el primer texto de la Norma ISAD $(G)$, los archiveros españoles teníamos aprendidos, e incluso asumidos, bastantes conceptos en torno a la descripción que, enumerados, pueden darnos, nuestro estado de la cuestión, en la antesala de la aplicación de dicha Norma:

- la "descripción archivística" era una manifestación específica del análisis documental, aplicado a los documentos de archivo y a sus diferentes agrupaciones documentales, naturales o artificiales. Afectaba a cualquier documento de archivo, con independencia de su soporte o de su edad

- era representación, antes que interpretación, y no, desde luego, reproducción

- como tarea archivística era una y así la definíamos sin perjuicio de sus resultados o variadas manifestaciones -los instrumentos de descripción-que también definíamos y acotábamos uno por uno, con independencia de la configuración que cada uno de nosotros defendía para ellos. Describir no tenía más fin que confeccionar los instrumentos de descripción 


\section{La Norma ISAD (G) va a hacer posible un medio de comunicación universal que nosotros hemos de agilizar y facilitar con un lenguaje comprensible. No nos empeñemos en verla difícil y, menos aún, en hacerla difícil.}

- la descripción exigía identificación, extracto de contenido y localización

- se basaba en la jerarquía del fondo como fiel trasunto del principio de procedencia y en la herencia de la información que luego se reconocerán como fundamentos esenciales de la descripción multinivel3. Es cierto que no habíamos inventado el determinativo pero sí aplicábamos la descripción multinivel ${ }^{4}$ y curiosa y precisamente lo hacíamos a los fondos de Archivos administrativos ${ }^{5}$

- la jerarquía del fondo se manifestaba a partir de sus partes componentes que determinaban los diferentes y sucesivos niveles de descripción (fondo, sección, subsección, serie, subserie, documento o pieza documental simple o compuesta)

- la descripción presuponía la organización, entendida en una doble vertiente de clasificación y ordenación. De aquí nuestra preocupación por buscar modelos de cuadros de clasificación para fondos semejantes

- la descripción en un Archivo exigía una planificación que iba de lo general a lo particular. Se empezaba por el fondo y se concluía por los documentos (guías, inventarios, catálogos) 6

- los instrumentos de descripción mantenían un paralelismo con los principales niveles de descripción

- los instrumentos de descripción eran los que a manera de puente unían los Archivos y sus contenidos con los usuarios

- la formalización de la descripción se realizaba a partir de los elementos de descripción que todavía distinguíamos y agrupábamos en caracteres internos, caracteres externos y datos archivísticos y cada nivel y cada instrumento de descripción exigía unos elementos propios

- las agrupaciones documentales, al margen del fondo, consideradas artificiales (colecciones, secciones o series facticias) entendíamos que también exigían la descripción archivística7

- habíamos hecho objeto de la descripción a los Archivos, como instituciones, elaborando para elloslas correspondientes guías.

Hasta aquí lo que pensábamos y muchos veníamos practicando, como la bibliografía testimonia. Otra cosa era la diversidad de aplicaciones prácticas que no hacían sino reclamar por su normalización. De aquí mi disconformidad con quien ha querido minimizar la aportación española a la descripción reduciéndola a un simple debate sobre la forma de elaborar los inventarios y los catálogos.

Y en esto llegó la Norma, que no es sino un formato normalizado para esa tarea única que es la descripción archivística para permitir -a nivel internacional- el intercambio de información de los documentos de archivo. Su objetivo inmediato no era hacer instrumentos de descripción, pero a partir de ella podíamos elaborarlos. Dicho formato permitía a través de Áreas o campos agrupar a todos los elementos posibles de descripción para, yendo de lo general a lo particular, sin repetir información permitirnos describir el fondo y luego sucesivamente sus partes componentes o niveles y en última instancia, podíamos confeccionar los diferentes instrumentos de descripción.

No había, pues, la más mínima contradicción entre nuestra posición y las exigencias de la Norma. Esto tenía que ser así porque la lógica de la Norma es lógica archivística y no podía ir contra una teoría hispana que ha tenido como sustento dicha lógica.

La mayoría de los principios y conceptos volcados en la Norma no eran sino los que defendíamos. Los nuestros, incluso con una apertura y precisión superiores. En cuanto a los elementos de descripción prácticamente eran los de uso habitual entre nosotros, salvando algunas denominaciones.

Fue ya el propio Hugo Stibbe, en septiembre de 1993, en el Seminario celebrado en México -previo a la difusión del primer texto- quien reconocía que lo expuesto en la Norma no era nuevo, ni extraño a la teoría archivística y a las prácticas convencionales.

Lo novedoso, sin embargo, a mi modo de ver, era solo la dimensión formal que parecía darle aspecto 
de ajena. En esta constatación he basado siempre mi defensa y apoyo a su aplicación.

A pesar de todo lo expuesto, que no es sino una evidencia, el grado de compromiso con las exigencias de la uniformación y la disciplina que supone la cuadriculación para los elementos, en Áreas con denominaciones propias -alguna ciertamente confusa ${ }^{8}$ - han sido quizá las trabas que han propiciado, en nuestro país, la resistencia inicial al acercamiento y al conocimiento de la Norma ISAD(G). Dicha resistencia ha podido estar favorecida por la dificultad en las aplicaciones prácticas cuando algún archivero no se ha querido despojar de posiciones tradicionales e historicistas.

Solo quiero recalcar con esta introducción que no tenía que haber existido desinterés entonces y ahora no puede haber lugar para el rechazo, cuando esta Norma viene a satisfacer dilatadas reivindicaciones homogeneizadoras y para más abundamiento se adecua a nuestros planteamientos y concepciones esenciales en la materia.

Lo dicho no obsta para que la adaptación y sobre todo la aplicación generalizada en España requiera un intenso debate que no debe alargarse y que, en estos momentos, tiene una canalización oficial a partir de la elaboración de unas reglas nacionales de aplicación. Todos debemos sentirnos comprometidos. El tiempo empleado en esa elaboración que, insisto, no debe dilatarse y la rentabilización de su uso, serán obra de todos y cada uno de nosotros.

\section{Qué es y qué supone la norma ISAD(G)}

Decir qué es y que supone la primera Norma archivística Internacional que inició su andadura trece años atrás, puede resultar a estas alturas tan improcedente, como chocante.

Sin embargo dando por sentado que todos los archiveros españoles la conocen, dudo que todos estén describiendo con ella de forma habitual en sus Archivos y menos aún que la mayoría se haya ocupado de analizarla, compararla y aplicarla hasta sus últimas consecuencias.

Recientemente al invitar a algún archivero a formar parte del grupo de trabajo en mi Comunidad con vistas a aportar sugerencias y observaciones al grupo que está elaborando las Reglas Nacionales de descripción, he recibido su negativa a participar argumentando que el trabajo de archivo le impedía tener tiempo para estudiarla y experimentarla. ¡Cómo si las Normas y su aplicación fueran algo distinto de las exigencias del diario tratamiento archivístico!

Valga este comentario que no busca sino justificar lo que voy a seguir exponiendo, sobre la referida Norma, por cuanto debe ser sobradamente conocido para quienes se han adentrado suficientemente en sus contenidos, haciéndola compañera de viaje.
La Norma no es un standard para los instrumentos de descripción, sino un formato único para describir los documentos de archivo.

Dicho formato permite realizar una descripción estandarizada de cualquier agrupación de documentos (fondo, subfondo o sección, serie, colección) o de cualquier documento individualizado pero relacionado con lo anterior, ya sea una unidad documental simple o compuesta, y que, partiendo del reconocimiento de la estructura jerárquica del fondo, obligará a describir primero el fondo y sucesivamente sus partes componentes, en una sucesión de niveles?

Es una Norma archivística y como tal, profesional. No es una Norma jurídica que obligue, aunque tendría que obligar a todos los archiveros por convencimiento, o, en todo caso, por conveniencia.

Como tal exige el consenso de todos, no a mano alzada, sino a partir de una aplicación comprometida. Y no me cabe duda que, en ese consenso que ahora se busca con las Normas Nacionales, subyacerán insatisfacciones individuales pero los beneficios siempre serán buenos en términos generales.

Ni el principio que informa a la Norma que va de lo general a lo particular, ni el concepto jerárquico del fondo sustentado en el principio de procedencia, ni siquiera ese concepto -aparentemente novedosode descripción multinivel son desconocidos -como ya apunte al principio- en la teoría hispana. De aquí que la Norma no puede ser un juego para un rato libre, sino un compromiso inserto en la cotidianeidad del trabajo archivístico.

Por otra parte la formalización de la Norma que no viene sino a partir de la cumplimentación de los elementos de descripción-todos reconocibles en nuestra teoría- tampoco resulta novedoso, salvo que todos deberemos encajar a cada uno, en las Áreas preestablecidas.

Insisto en que la Norma no viene a trastocar, sino a reafirmar nuestra teoría archivística. La Norma no es revolución, sino evolución y desarrollo a partir de una aplicación disciplinada de todo lo que veníamos practicando en materia de descripción.

Siendo la Norma ISAD(G) y su complementaria la ISAAR(CPF) para el control de autoridades, normas exclusivamente para la descripción, su uso no puede extrapolarse a otras funciones, ni remediar con ella deficiencias o carencias en el resto de nuestro trabajo.

Las Normas no vendrán en nuestra ayuda para la organización que deberá ser previa a la descripción. Su aplicación determinará, el replanteamiento de funciones previas o la revisión de situaciones poco rigurosas, justificadas en algunos casos por la tradición.

Lo que sí determinarán será el retoque de nuestro vocabulario y con éste, el conceptual. 
¿Cómo podremos aplicar la Norma ISAD $(G)$ a la tradicional "Sección" XII del Archivo General de Indias, sino es a partir del reconocimiento y delimitación de los dos fondos que la integran? Y casos análogos pueden ser la "sección" de Consejos del Archivo Histórico Nacional o las "secciones" de Beneficencia de bastantes Archivos de Diputaciones provinciales. ¿Se puede aplicar la Norma al denominado fondo de un Archivo Municipal identificado con todos los documentos que integran su depósito, incluidos los correspondientes al juzgado de paz, a los fondos privados y a los protocolos notariales?

En esa revisión de "situaciones incorrectas" o poco rigurosas entran de lleno los cuadros de clasificación, tanto los de Archivos o de fondos y colecciones, como los de cada uno de los respectivos fondos. Y en esos cuadros, los fondos que tienen nombre propio -nombre archivístico- y no título, habrán de figurar con dicha denominación que trasladaremos al formulario de la Norma.

La revisión del lenguaje nos llevará, entre otras cuestiones, no solo a acotar el término fondo sino a evitar confundido con otras realidades, como es el Archivo o las colecciones.

Hace un momento dije que la Norma no venía a trastocar nuestra teoría archivística, pero sí viene a regenerar, en más de un caso, algunas manifestaciones de nuestro trabajo específico, incluso más allá de la propia descripción. En este sentido algunos formularios que sustentan algunas Bases de datos habrán de ser retocados. Es el caso de alguna base de datos elaborada para el censo del Patrimonio documental, donde Archivos y fondos se confunden de tal manera que da igual el Archivo Municipal de tal lugar como el fondo del Ayuntamiento de dicho lugar. No es éste el único caso. En un boletín informativo, de agosto de este año al referirse a grupos de trabajo para elaborar normas particulares, sorprende que al referirse a fondos públicos (notariales, judiciales, juntas electorales) también se enumeren como tales a los Archivos Autonómicos y a los Archivos Municipales, cuando quizá delimitando cada fondo, sin confundirlo con un Archivo, no tendrían que ser tantas las normas particulares.

La Norma ISAD(G) y su complementaria la ISAAR (CPF) de control de autoridades -menos conocida y mucho menos aplicada que la primera- no viene ni a arrinconar, ni a complicar. El objetivo de la descripción archivística es lograr una vía de comunicación fácil y fluida entre los usuarios y la información contenida en los Archivos. Se nos ha tachado más de una vez por la dificultad que ponemos en hacer accesibles los documentos a los demás a partir de instrumentos poco amigables y difícilmente inteligibles para cualquiera. La Norma va a hacer posible un medio de comunicación universal que nosotros hemos de agilizar y facilitar con un lenguaje comprensible. No nos empeñemos en verla difícil y, menos aún, en hacerla difícil.
Proceso de revisión de las normas de descripción y el nuevo texto de la norma ISAD(G)

Dicho lo anterior y antes de encarar el estado de la situación en España, es conveniente hacer un breve repaso del proceso de revisión, sin remontarnos a la Historia de sus inicios, suficientemente difundidos y conocidos, para situarnos en el texto de la segunda versión.

Como sabemos la primera versión de la Norma Isad(G), aunque de 1994, se divulgó en España en 1995. Desde ese momento el texto estuvo sometido, a lo largo de cinco años, a su preceptiva revisión.

Desde el Congreso de Pekín, en 1996, la Comisión ad hoc trabajó e impulsó la revisión y el desarrollo de dichas Normas. A finales de septiembre de 1998 se habían recibido 33 informes de 25 países diferentes con sugerencias y observaciones, constituyendo un compendio de un centenar de páginas. Todos reconocían el valor teórico y práctico y sin pretender cambios substanciales -a los que no se tenía opción-, también todos coincidían en la necesidad de enmiendas para algunos elementos. Así para el título, para las fechas, para la documentación asociada.

El conjunto de dichas observaciones ha determinado algunas mejoras en la segunda versión de la Norma Isad(G) de 1999 que, como todos sabemos, fue suficientemente difundida en Sevilla con ocasión del XIV Congreso Internacional, junto con la I ${ }^{a}$ versión de la ISAAR(CPF).

Aunque Vitale insiste en que la declaración de la finalidad de la Norma en esta nueva versión ya supone una novedad, entiendo que no lo es tanto por cuanto desde el primer documento de 1990 con la Declaración de los principios de la Norma se reconocía ya que con ellas se intentaba fijar los principios que regularan internacionalmente la descripción a partir de un formato único (es decir acotar teóricamente la descripción) y por otra, a partir de ese formato, conseguir la consistencia de las representaciones o descripciones que podrán dar lugar a los instrumentos de descripción. Lo que no era sino discernir entre la teoría de la descripción y su aplicación o resultados, materializados en alguna medida en dichos instrumentos.

El segundo texto de la Norma Isad(G), que es el que habremos de utilizar por el momento, como era de esperar, no modifica la estructura primera del formulario, ni la disposición y reparto de los elementos. Con todo, existen algunas novedades y mejoras, sin que aquí necesariamente hayan de concluir los cambios en el futuro.

Elena Lobato Yanes y Antonia Heredia adelantaron los primeros comentarios sobre dichas modificaciones en el Boletín de Acal10 Una y otra reconocen la mayor flexibilidad y la universalidad de su aplicación. Flexibilidad que, a mi modo de ver, no 
puede llevarnos a la arbitrariedad de aplicación, so peligro de colocarnos en el campo de la desnormalización. De aquí que la flexibilidad propugnada por la segunda versión de la Norma puede ser buena hasta tanto no se convierta en discrecionalidad. La más importante manifestación de esa flexibilidad quizá sea la recomendación expresa de elaborar Normas Nacionales compatibles con las Normas Internacionales. En cuanto a la ampliación de la aplicación, el nuevo texto concluye que no sólo afectará a los fondos permanentes o históricos y sus partes, sino también a los fondos abiertos, a las colecciones y a los documentos especiales o con distintos soportes.

Novedad importante, de carácter general, es sin duda el reconocimiento del productor como elemento indispensable que se añade a los cinco reconocidos, como tales, del Área primera de identificación (código de referencia, título, fechas, extensión, nivel de descripción) pero que siendo indispensable mantiene su sitio en el Área de contexto cuando, desde mi punto de vista, no hay elemento más esencial para la identificación de los documentos de archivo que el que se refiere a la procedencia.

Y por lo que a la procedencia se refiere, lo que la Norma continúa sin contemplar, de forma clara, es la necesidad de reconocer dos estadios, cuando hablamos de productor, uno directamente relacionado con el fondo y el otro con la serie documental, productores que hereda automáticamente la unidad documental.

Por lo que afecta a las seis Áreas existentes se mantienen con sus denominaciones, aunque se añade una séptima denominada "Área de control de la descripción" que hace referencia al autor de la descripción, a la fecha de la descripción y a las reglas utilizadas para la misma. A mi modo de ver, es un área bien diferente a las anteriores por cuanto si las seis existentes contienen información referida exclusivamente a los documentos que se describen, ésta recoge datos que nada tienen que ver con los propios documentos y su producción y que serían parte de los créditos de una edición.

En cuanto a las modificaciones referidas en particular a los elementos, hay que constatar que se mantiene el número de 26 , aunque se ha introducido alguno nuevo compensado con la agrupación de otros ya existentes. Dichas variaciones afectan al título, a las fechas, a la Historia de la custodia, a la lengua, a las características físicas. En cuanto al título, no se ha conseguido erradicar el término pero al declarar su objetivo se reconoce que no es otro que denominar a la unidad de descripción lo que viene a satisfacer en escasa medida las reivindicaciones que para dicho elemento se han reclamado desde bastantes frentes.

En cuanto a las "fechas" se han unificado, arrinconando la diversidad de referencias cronológicas, adecuándose más fácilmente a nuestro posicionamiento.
En cuanto a la "Historia de la custodia" se ha modificado su denominación por "Historia archivística" ampliando su contenido.

Al elemento "lengua", se ha añadido "escritura" que aún siendo algo distinto, al agruparlos ha permitido mantener el número inicial de elementos.

A las "características físicas" también se han añadido los requisitos técnicos.

\section{¿Dónde estamos en España? ¿A dónde vamos?}

El desinterés por la primera versión y, como consecuencia, su desconocimiento, se ha trocado bastante a la hora de la segunda versión.

En este momento contamos con lo siguiente: ha aumentado el interés aunque siga sin generalizarse el uso, la segunda versión de la ISAD(G) se ha decantado por la flexibilidad y ampliación de aplicación y además se nos ha dado la posibilidad de desarrollar unas Normas Nacionales. De aquí que, sean necesarias dosis importantes de colaboración, coordinación y coherencia para encarar el tema.

El interés queda testimoniado por los grupos de trabajo que están proliferando: Andalucía, Aragón, Cataluña, Archivos Estatales, Asociaciones, Comunidades Autónomas y, ni que decir tiene, en la Bibliografía.

La flexibilidad y la universalidad propugnadas ahora por la Norma no deberían sin embargo llevarnos a multiplicar las normas y a diversificarlas. La Norma que pretende ser un formato único para esa tarea única que es la descripción, viene a constatar que cada agrupación documental tiene características comunes, que las notas esenciales de un documento de archivo - del que el soporte o determinadas características físicas no son más que algo accesorio- se repiten y que unas y otras pueden extraerse para hacer representaciones semejantes. Las menciones legítimas a las peculiaridades de un Sistema de Archivos, cuando codifiquemos a un Archivo, o los datos requeridos para representar el contenido de las unidades documentales de una serie específica en una determinada institución, o el abundamiento en determinadas características físicas exigidas a los documentos gráficos no tienen porqué suponer nuevas normas, sino previsión del desarrollo para la cumplimentación de cada uno de los elementos a partir de esa variedad documental.

La posibilidad de elaboración de Normas Nacionales, estando ya aprobadas las Normas Internacionales, puede pero no debe dar lugar a dudas. No se trata de hacer normas diferentes con campos y elementos distintos, sino de adecuar las Internacionales a nuestra tradición, teoría y práctica, para conseguir una aplicación que no de lugar a la multiplicidad de 
interpretaciones que ahora, todavía, son posibles, aún con la flexibilidad pretendida.

Convivencia y compatibilidad de Normas Nacionales y de Normas Internacionales. Este es nuestro reto y como tal todos tendremos algo que decir y aportar.

Esta posibilidad que hemos de aprovechar, no ha de justificar, sin embargo, el aplazamiento de la aplicación de las Normas de descripción en cada Archivo.

Con todo la elaboración de estas Normas nacionales plantea una serie de cuestiones a la hora de la colaboración, la coordinación y la coherencia.

No creo que quepa duda que son los archiveros como colectivo a quienes toca la elaboración del texto.

Pero ¿quiénes, cómo, dónde? ¿A quién corresponde la elaboración de una metodología común de trabajo? ¿A quién la sanción de dichas Normas?: al Estado, a cada Autonomía, a la coordinadora de Asociaciones de archiveros?

Es un hecho que el Ministerio de Cultura ha aplazado más de lo conveniente el ejercicio de una coordinación que, desde mi punto de vista le corresponde como interlocutor a más alta instancia del CIA. Recientemente ha tomado las riendas convocando a todas las Comunidades Autónomas a formar un grupo de trabajo mientras que los grupos a que antes me refería están trabajando por su parte.

¿Cómo se coordinaran las conclusiones de todos los grupos? No puede haber más que unas Normas Nacionales compatibles con las Internacionales, y no debíamos contar más que con un Manual de aplicación de dichas Normas Nacionales. No cabe duda que disponer de una Norma no elimina las diversas posibilidades de interpretación, de aquí que las instrucciones o el Manual de aplicación deben reducir el número de esas posibilidades.

Hace tiempo me pronuncié en esta línea. Mi propuesta pretendía, con vistas a la operatividad, un solo grupo de trabajo de ámbito nacional y suficientemente representantivo, no en el sentido de que todos los Archivos y todas las Administraciones estuvieran representadas sino al modo y manera de un Comité de expertos -que no "Comité de sabios" como quizá alguien peyorativamente pretendió desvirtuarlo- donde la experiencia y el conocimiento del tema fuera requisito prioritario para la representatividad pretendida.

Sin embargo, así, y a estas alturas, contamos con más de un grupo de trabajo. Y lo que es más contamos con un texto oficial de la Norma en inglés, dos traducciones en castellanoll y otra en catalán. Cuatro versiones y un Manual'2, que así enunciado no hacen sino recordar los equívocos de la película inglesa. Equívocos que sí se están produciendo, por no saber a qué carta jugar y siguen dando ocasión a una gran diversidad interpretativa.
A simple vista hay bastante coincidencia entre las dos traducciones en castellano que, lógicamente han partido de la versión inglesa, sin embargo mientras que la primera opta por una traducción literal, la del Ministerio trata de utilizar términos y conceptos que representan en buena medida la tradición y teoría hispanas.

Así las cosas, inevitablemente, los dos textos llevan al uso de terminología y conceptos no siempre coincidentes que pueden dar pie a cierta discrepancia.

Quiero, referirme a algo, que pudiera interpretarse como baladí, pero que va más allá de una aparente opción terminológica. Se trata de las respectivas denominaciones de Área primera -reconocida como principal e indispensable-: Área de mención de identidad, Área de identificación o Área de identificación y localización ${ }^{13}$ (esta última utilizada en la traducción catalana).

Me da la sensación por las diferentes interpretaciones que se deducen de los ejemplos aportados que cada una de las traducciones puede llevarnos a aplicaciones distintas, cuando precisamente es ésta el Área que debe estar mejor delimitada, para no dar lugar a equívocos. ¿Qué queremos decir con identidad o con identificación? 14.

Cuando nos referimos al código de identidad sabemos que es algo al margen de concepciones archivísticas, cuando la identificación, en cambio, es un término alusivo a una función archivística perfectamente definida.

A pesar de la aparente cercanía de los textos de las distintas traducciones y del Manual de descripción multinivel|15, como he dicho, una vez más habremos de ponernos de acuerdo en la definición y uso de términos archivísticos que entresaco de dichos textos: unidad documental, unidad documental superior, unidad documental subordinada, unidad archivística, unidad de instalación, materiales archivísticos, gestión archivística, identificación, mención de identidad, órgano productor, sujeto productor, organismo productor original, materiales relacionados, entidad archivística, entre otros.

El logro de esa coincidencia determinará la matización de algunas definiciones que, traducidas literalmente del inglés, no resultan convincentes ${ }^{16} \mathrm{O}$ la precisión de algunos conceptos que siguen estando por consensuar, como es el caso de "subserie". Además de consensuar el uso de términos, habremos de pulir la redacción del propio texto que a veces resulta poco inteligible quizá en ese afán de reproducción de la versión inglesa ${ }^{17}$.

Habremos de evitar planteamientos contradictorios que entorpezcan la comprensión de la aplicación. Pueden ser indicativos algunos ejemplos obtenidos de las traducciones en castellano. Así la signatura, considerada como número de control 
en el elemento "código de referencia", no debería estimarse como "título" de la unidad de localización, ni puede formar parte del elemento volumen o extensión, ni menos aún formalizarse en el Área de Notas. De igual manera, el tema y la materia principal que tendrían que ser sinónimos, no habrían de formalizarse sino a través de un único elemento que debería ser el contenido. La discrecionalidad en esto, puede resultar nada conveniente.

Habremos, también, de evitar desvirtuaciones. Así puede resultar de la identificación del productor con el coleccionista cuando, a afectos de la descripción archivística éste tendría que valernos solo para dar nombre a la colección por él recopilada o para hacer referencia al mismo en la recopilación histórica de dicha colección.

Así las cosas, desde abril pasado se ha puesto en marcha un grupo de trabajo convocado por el Ministerio de Cultura con representación de todas las Comunidades autónomas con el fin de elaborar unas Normas Nacionales de descripción archivística, que más que tales son unas Normas nacionales de aplicación de las Normas Internacionales.

El grupo ha tenido tres reuniones, la última el 5 y 6 de noviembre. Ni qué decir tiene que la diversidad de interpretación de las Normas Internacionales es tal, que justifica sin lugar a dudas la elaboración de unas Normas Nacionales que minimicen tal posibilidad de interpretación. Este inevitable punto de partida está retrasando en cierta medida los acuerdos para un consenso, hasta el punto que la dedicación a elementos aparentemente tan faltos de conflictividad, como el código de referencia, hayan dilatado el tiempo de los debates quizá más de lo previsto. Con todo, la discusión de este elemento nos va a llevar a la adopción de un Registro único de códigos de Archivos a partir de un Registro de Archivos Estatales compatible con los Registros Autonómicos de códigos de Archivos de cada región y que evidencia una vez más que la signatura no puede formar parte del código de referencia.

Con todo es evidente que el debate se prevé substancioso y en este punto solo me voy a permitir referirme a algunos elementos y situaciones que a mi modo de ver pueden ser puntos débiles de la Norma. Ni que decir tiene que alguno de los debates más conflictivos estarán en torno a la delimitación, acotación y explicitación del título que necesariamente está ligado a la definición de los diferentes niveles de descripción. Amén de la fijación del sitio de la signatura o localización de los documentos descritos dentro de un Archivo.

Considero que es el elemento traducido y llamado "título" el que viene dando desde el principio una insatisfacción más generalizada que empieza por esa denominación genérica, poco ajustada a la realidad de los documentos de archivo, y continúa por la diversidad denominativa de sus acepciones (título for- mal, título atribuido, a las que se suman, según el MDM, título oficial, título formal paralelo, título oficial paralelo, título combinado). Estaba en la primera traducción del Ministerio de Cultura y ha continuado en la segunda, aunque hay que reconocer que en ésta segunda ha quedado matizado tanto en la definición que aparece en el glosario ("palabra, frase, carácter o grupo de caracteres que sirve para denominar la unidad de descripción") como en el objetivo para este elemento que no es otro que "denominar la unidad de descripción".

Ni los escasos ejemplos aportados por la traducción del Ministerio, ni los abundantes ofrecidos en el MDM según las diferentes acepciones del título, ayudan a resolver cuestiones conceptuales, que deberían ser previas a la formalización de la información referida a este elemento.

Título es un término que no figura en el Diccionario de terminología archivística editado por la Subdirección de Archivos Estatales. En el glosario de la segunda traducción de la Norma del Ministerio se define, ya lo hemos dicho, como "palabra, frase o grupo de caracteres que sirve para denominar la unidad de descripción". Es decir, título igual a nombre de unidad de descripción. De aquí que la diversidad de unidades de descripción, conlleve diversidad de denominaciones. Ahora bien, esos nombres ¿pueden ser arbitrarios o son nombres propios? $\mathrm{Pa}$ ra precisarlos se dice, según el MDM, que requieren "adecuación" al "contenido" y "concisión sin renunciar a dar información esencial". En la traducción del Ministerio se dice que se puede incluir "el tema".

Cuando hablamos de adecuación al contenido o de tema, y a la vista de los ejemplos aportados ino podríamos estar traspasando la frontera, situándonos en otro elemento preciso, como es el contenido propiamente dicho?

Insisto en que los ejemplos aportados en cada caso a veces, no resultan excesivamente convincentes. ¿Dónde termina el título y empieza el contenido? ¿Qué datos debe contener según cada nivel? ¿La tipología documental debe ser parte del título? Y iel autor? Y iel destinatario? Y ¿el asunto o materia? Y ilos datos cronológicos? ¿Qué orden deben tener los datos?!

Se dice que el título en su acepción de "formal" puede tomarse, cuando figure, de un lugar destacado del documento y en tal ocasión "se transcribe sin modificaciones substanciales" (MDM, p. 33). ¿Nos limitaremos a reproducir, a sabiendas de que la información en todo o en parte no es correcta? Y aún siendo la información adecuada ¿nos limitamos a reproducir o a abreviar, evitando la verdadera "representación" que debe ser consubstancial a la descripción archivística? ¿Estamos acercándonos a las prácticas de catalogación de manuscritos en las Bibliotecas? Se me viene esta idea a la cabeza cuando compruebo la escasa referencia a la tipología documental. Aunque tal 
concepto figura definido en el glosario, a la hora de la práctica hay una pérdida de peso específico para el mismo. No se dice expresamente que la tipología documental es dato importante para precisar el nombre ("título") de la serie y el de la unidad documental y de hecho se elude ${ }^{19}$. Cuando, en la práctica, esa tipología nos adelanta, nos enriquece y precisa con su simple enunciado el contenido del documento o documentos que describimos. Y no sólo eso, sino que su uso, en muchos casos, nos simplifica el proceso de descripción archivística y el ofrecimiento de sus resultados, facilitando el acceso a los usuarios.

La nueva versión de la Norma, al encontrar dificultad de satisfacer la tradición y prácticas de toda la Comunidad archivística, ha abogado por una flexibilidad que permita la conciliación con las denominadas normas nacionales. Esta adecuación debía permitir, en nuestro caso, la admisión de conceptos y elementos propios de la Diplomática que tan provechoso papel ha jugado y sigue jugando a la hora de la descripción archivística.

Otra última cuestión. Cuando describimos un traslado y le damos título ¿a qué recurrimos? ¿al traslado que es el documento que tenemos delante $o$ al documento trasladado?

$\mathrm{Ni}$ que decir tiene que otro punto importante es el que afecta a los niveles de descripción. Luís Martínez ya adelantó en un interesante trabajo, relativamente reciente, a partir de un amplio espectro de incongruencias e indefiniciones detectadas en el panorama archivístico español, muchas reflexiones al respecto ${ }^{20}$. Ni que decir tiene que las agrupaciones de los documentos de archivo son algunas más que las reconocidas como resultado de la realidad jerárquica del fondo. Existen otras, como la colección o la fracción de fondo o como pueden ser el "grupo de fondos", el Archivo y la unidad de instalación que habrá que discutir ${ }^{21}$. ¿Cuántos y cuáles son los niveles de descripción?

De aquí que si el nivel de descripción es un concepto estable, las agrupaciones documentales que lo representan pueden no serlo tanto hasta el punto que habremos de plantearnos ¿dónde empieza y termina un fondo? Los recientes textos normativos de las Comunidades autónomas ofrecen distintos posicionamientos. Un fondo tanto puede ser la producción documental de una Comunidad Autónoma, como puede serlo la producción documental de una Consejería 22 . En relación con esto la tendencia actual a los cuadros de clasificación funcionales no hace sino mostrarnos la conveniencia de no aferrarnos a las estructuras orgánicas, optando por la funcional, y es lógico que la evolución del concepto de fondo tras- ciende a sus partes y llegada aquí me pregunto ¿no estaremos de alguna manera acercándonos a la acepción de serie francesa?

En conexión con la discusión de los niveles que puede ser substanciosa, va a estar la acotación y delimitación de los instrumentos de descripción que nos llevaran entre otros resultados a contemplar si es posible a partir de la Norma ISAD(G) elaborar Guías de Archivo -Pedro López ha mostrado su postura y su experiencia al respecto ${ }^{23}$ - o si también podemos confeccionar instrumentos nuevos como pueden ser los censos de fondos y colecciones del Patrimonio documental, que no lo censos de Archivos 24

Hay pues bastante tela que cortar.

Para concluir, alguna reflexión. Quizá, no estemos dando una visión exacta de la cuestión cuando se dice que el debate de la normalización en España ha estado centrado solo en la terminología genérica y específica de los instrumentos de descripción, aunque así haya sido para algunos.

Lo que si es claro es que, a estas alturas, no importan tanto los nombres de los instrumentos, como la posibilidad de instrumentalizar de una forma inmediata la comunicación directa con el usuario dando satisfacción a la información requerida por éste sin que tenga que entrar a discernir lo que es una guía, un inventario o un catálogo. Y esto no quiere decir que hayamos de hacer tabla rasa con los instrumentos de descripción.

Sin entrar en una recapitulación de tareas pendientes -bastantes- éstas no tienen más fin que el logro de dos objetivos relacionados:

- elaboración y difusión de un único texto oficial con las Normas Nacionales de aplicación de las Normas Internacionales de descripción archivística.

- redacción y edición de un Manual de aplicación de dichas Normas Nacionales, con una ejemplificación tan variada como suficiente que reduzca al máximo las interpretaciones.

Término abundando en la idea de que la descripción trasciende a todas las funciones archivísticas, a sus principios y al vocabulario profesional de aquí que las Normas que la sustentan, siendo específicas, no pueden suponer una acotación independiente dentro de una aplicación informática de gestión documental integrada. Considero que las dos Normas Internacionales, mucho más cercanas y familiares y menos susceptibles de interpretación, a partir de las Normas Nacionales, no tienen porque cambiar nuestro trabajo pero sin duda vendrán a regenerarlo. 
I. VITALI, Stefano: "El desenvolupament d'standars de descripció internacionales: la segona edició de la norma ISAD(G)" Lligall I7, VIII, Actas VII Jornadas Archivísticas de Cataluña, p. 13-22.

2. Cfr. Actas de Documentación y Archivos de la colonización española, Madrid, Ministerio de Cultura, 1980;

HEREDIA HERRERA, Antonia: "Inventarios y catálogos" Boletín de ANABAD, XXX, 2, 1980, p. 239-242.

3. Declaración de Principios para la descripción archivística

4. En este sentido, no puedo sino remitirme a una ilustración y a un texto que testimonian el planteamiento de la descripción multinivel, recogidos respectivamente en dos manuales españoles: CORTES ALONSO, Vicenta: Manual de Archivos municipales, ANABAD, Madrid, 1992, p. I 12 y HEREDIA HERRERA, Antonia: Archivística General. Teoría y práctica, Sevilla, 1986, p. 434 y ss.

5. Despojados como estabamos de posiciones historicistas a ultranza, por eso reclamamos para la documentación administrativa la aplicación de la Norma ISAD(G). Cfr. HEREDIA HERRERA, Antonia: La Norma ISAD(G) y su terminología, Madrid, 1995, p.

6. HEREDIA HERRERA, A.: "Planificación de los instrumentos en los archivos". Boletín interamericano de archivos, Córdoba (Argentina) VIII, 1980, p.87-95.

7. De aquí que reclamáramos muy pronto para las colecciones, la aplicación de la Norma.

8. Hemos de reconocer, aunque nos pese, la fuerte influencia de reglas procedentes del ámbito bibliotecario que se han instalado con firmeza y en algún caso pueden obstaculizar la confección de nuestras reglas nacionales. Es el caso de la primera y de la segunda Áreas. El término "título" dado a uno de los elementos de descripción, es una clara referencia a cuanto digo.

Si se tratara de un simple término para el que buscáramos su equivalente en Archivística no existiría problema. Lo grave es que se trata de una intromisión conceptual, que nos lleva incluso a esas concepciones y tipificaciones artificiosas del título (formal, atribuido, oficial, formal paralelo, y título oficial paralelo) ajenas a nuestras prácticas más afianzadas. Más adelante insistiremos.

9. Nos viene a la memoria el machacón mensaje de algún Manual español que insistía que no se podrían hacer los catálogos sin estar hechos los inventarios, en un momento en que la descripción era sinónima de catalogación y el instrumento de descripción por antonomasia, el catálogo.

10."Archivamos". Boletín de ACAL, n 36-37, 2000.

II. La primera realizada por Carlos Travesí de Diego, Elena Lobato Yanes y Juan José Generelo Lanaspa y la segunda, por el Ministerio de Cultura hecha por Asunción Benloch, $M^{a}$ Dolores Carnicer Arribas, Blanca Desantes Fernández y Guadalupe Moreno López.

12. "Manual de descripción multinivel. Propuesta de adaptación de las normas internacionales de descripción archivística", redactado por Carlos TRAVESÍ, Juan José GENERELO y José L. BONAL y que parte de la primera de las traducciones en castellano. Editado por la Junta de Castilla-León, en el año 2000

13. Es la denominación que para esta Área vengo defendiendo desde 1995, según está publicado.

14. Cfr. HEREDIA HERRERA, A.: "La nueva versión de la Norma ISAD(G), Archivamos, nos 36-37, 2000, p. 6 y 7.

15. Cfr. nota |I.
16. Cfr. definición de serie en los textos de las dos traducciones. Cuando se traduce que los documentos que componen una serie "tienen una forma particular" ¿qué se quiere decir archivísticamente en castellano?

17. Así cuando se define el objetivo del elemento código de referencia: "identificar de un modo único la unidad de descripción y establecer el vínculo con la descripción que la representa". Quizá este objetivo no es del elemento en cuestión, sino de todo el Área. Quizá hablar de localización sería más comprensible que "establecer el vínculo con la descripción que la representa".

18. Así también cuando se mantiene el término de "materiales archivísticos" que no pueden ser sino documentos de archivo o documentos tratados como tales. $\bigcirc$ la redundancia de "existencia y localización de originales" que se evitaría suprimiendo existencia, o la identificación de la unidad documental compuesta con solo el expediente. También optar por "forma de ingreso", antes que por "Fuentes inmediatas de adquisición y transferencia".

18. Algunos ejemplos aportados al MDM nos, dan pie a estas preguntas. Así:

"I.2. título: Juan Sánchez vende una casa en Tardajos a Antonio Núñez (pág. 42)

(destinatario) (autor) (contenido)

I.2. título: Carta de Martínez de la Rosa al General Espartero felicitándolo por ..." (pág. 63)

(tipología) (autor) (destinatario) (contenido)

19. Cfr. en MDM, pág. 42.

20. MARTíNEZ GARCÍA, Luís: "Los principios de la descripción". Archivística, Boletín de ANABAD, n I, 1999.

21. CARNICER ARRIBAS, Ma Dolores; GENERELO LANASPA, Juan José: "Hacia una aplicación uniforme de $\operatorname{ISAD}(\mathrm{G})$ : los niveles de descripción" en TABULA: Normalizar la descripción archivística. Modelos, propuestas y herramientas, $\mathrm{n}^{\circ} 4$, 1999, págs. 139-170.

22. Durante algún tiempo he sentido cierta repugnancia a admitir como fondo toda la producción documental de una Comunidad Autónoma. Sin embargo, la dedicación reciente a cuestiones de valoración y selección de series documentales en un Archivo Intermedio como es el General de Andalucía y la opción por cuadros funcionales, me están determinando a la recapitulación por cuanto las propuestas de conservación o de eliminación pueden ser más coherentes.

23. En la introducción de la Guía del Archivo General de Andalucía y catálogo de sus fondos y colecciones, Sevilla, 2000 me posicionaba al respecto. Personalmente he reclamado la Norma Isad(G) para cualquier documento de archivo y para cualquier agrupación de los mismos y sin perjuicio de que las definiciones de Archivo y de fondo se superponen en los textos legales siendo preciso diferenciar entre Archivos, como instituciones, y fondos constitutivos del Patrimonio documental, estimo que es difícil hacer una Guía para un Archivo, considerado una institución. Y digo, Guía al estilo y manera que veníamos haciéndolo, por cuanto existen muchos datos referidos a dicha institución cuya cumplimentación no está prevista en la Norma.

24. La Orden de 6 de marzo de 200 l de la Consejería de Cultura de la Junta de Andalucía tiene previsto elaborar el Censo de fondos y colecciones constitutivos del Patrimonio documental a partir de las Normas ISAD(G) e ISAAR(CPF) que completará la información del Censo de Archivos Andaluces que no está elaborado a partir de las Normas de descripción archivística. 